\title{
Two-Step Esterification-Hydrogenation of Bio-Oil to Alcohols and Esters over Raney Ni Catalysts
}

\author{
Ying $X u^{1,2,3}$, Limin Zhang 1,2,3, Wei Lv 1,2,3,*, Chenguang Wang ${ }^{1,2,3}$, Congwei Wang 1,2,3, Xinghua Zhang 1,2,3, \\ Qi Zhang ${ }^{1,2,3}$ and Longlong Ma ${ }^{1,2,3, *}$
}

1 Institute of Energy Conversion, Chinese Academy of Sciences, Guangzhou 510640, China; xuying@ms.giec.ac.cn (Y.X.); zhanglm@ms.giec.ac.cn (L.Z.); wangcg@ms.giec.ac.cn (C.W.); wangcw@ms.giec.ac.cn (C.W.); zhangxh@ms.giec.ac.cn (X.Z.); zhangqi@ms.giec.ac.cn (Q.Z.)

2 Key Laboratory of Renewable Energy, Chinese Academy of Sciences, Guangzhou 510640, China

3 Guangdong Key Laboratory of New and Renewable Energy Research and Development, Guangzhou 510640, China

* Correspondence: lvwei@ms.giec.ac.cn (W.L.); mall@ms.giec.ac.cn (L.M.); Tel.: +86-020-87048614 (W.L.); +86-020-87057673 (L.M.)

Citation: Xu, Y.; Zhang, L.; Lv, W.; Wang, C.; Wang, C.; Zhang, X.; Zhang, Q.; Ma, L. Two-Step EsterificationHydrogenation of Bio-Oil to Alcohols and Esters over Raney Ni Catalysts. Catalysts 2021, 11, 818. https:// doi.org/10.3390/catal11070818

Academic Editors: Roman G. Kukushkin and Petr M. Yeletsky

Received: 5 April 2021

Accepted: 2 July 2021

Published: 5 July 2021

Publisher's Note: MDPI stays neutral with regard to jurisdictional claims in published maps and institutional affiliations.

Copyright: (c) 2021 by the authors. Licensee MDPI, Basel, Switzerland. This article is an open access article distributed under the terms and conditions of the Creative Commons Attribution (CC BY) license (https:// creativecommons.org/licenses/by/ $4.0 /)$.

\begin{abstract}
Fast pyrolysis bio-oil is very difficult to be used because of its acidity, instability, high degree of unsaturation, etc. Processes for property upgrading are necessary and required. In this study, three kinds of Raney Ni catalysts were prepared and used to investigate two-step esterificationhydrogenation (TEH) to upgrade the light fraction of bio-oil. The results show that the first step in esterification markedly decreased the content of active compounds such as acids and ketones and aldehydes and increased the content of alcohols and esters (from 10.53\% to $47.55 \%$ ), which improved the bio-oil stability and was favorable for the following hydrogenation reaction. The second step of TEH (hydrogenation) further improved the quality of the bio-oil over Raney Ni and metal-modified Raney Ni catalysts at $140{ }^{\circ} \mathrm{C}$. In particular, the Mo-RN catalyst displayed the best hydrogenation effect, with only $5.44 \%$ of acid content, and the stable component content reached $90.16 \%$. This may be attributed to the higher hydrogenation activity from Raney $\mathrm{Ni}$ combined with acid $\mathrm{MoO}_{\mathrm{x}}$ species and the thermal stability of the catalyst. Moreover, the obtained upgraded bio-oil mixture could be used as a solvent for raw bio-oil's esterification. Therefore, it has the potential to reduce methanol solvent usage and energy consumption for solvent separation during the two-step treatment of raw bio-oil in this context. Compared with the OHE (one-step esterification-hydrogenation) process, THE showed a better performance for raw bio-oil upgrading with higher alcohols and stable compounds, which is more favorable for the saturation and stability of bio-oil's complex components step by step.
\end{abstract}

Keywords: fast pyrolysis bio-oil; two-step esterification-hydrogenation (TEH); upgrading; modified Raney Ni catalysts; stable components; oxygenated fuel

\section{Introduction}

Bio-oil, the liquid product of biomass fast pyrolysis, exhibits a higher energy density and is widely regarded as a kind of green energy [1,2]. However, it remains challenging to upgrade bio-oil to high value-added products for a promising utilization prospect because of the complexly unstable oxygen-containing compounds (acids, ketones, aldehydes, phenols, etc.) in bio-oil [3-5]. In view of the multiple significant problems with biooil's properties [6-8], various upgrading techniques have been developed in the last two decades: in situ hydrogenation [9,10], hydrodeoxygenation [4,11], emulsification [12], catalytic cracking [13], steam reforming [14], esterification [15,16], etc. Among the techniques mentioned above, hydrogenation and esterification have received increasing interest due to their mild reaction conditions, especially the combined technologies of them [7,8,15-20]. Hydrogenation-esterification is significant in stabilizing the corrosive and reactive fractions of bio-oil, which is advantageous for the storage, transportation, further upgrading and 
combustion of bio-oil [15]. For instance, Shurong Wang et al. [7] found that the acid-rich fraction of bio-oil could be converted to alcohol or/and ester-rich compounds via catalytic hydrogenation-esterification over a $\mathrm{Cu} / \mathrm{SBA}-15$ catalyst. It was identified as an efficient coupling technology for bio-oil upgrading, with the fraction of acid compounds drastically declining from 25.0 to $0.4 \mathrm{wt} \%$. The fractions of aldehydes and organic acids (the primary components in bio-oil) were effectively converted to ester for stabilization by the approach of one-step hydrogenation-esterification (OHE) [15,16,18]. Wanjin Yu et al. [19] also devoted efforts to upgrading furfural and acetic acid via OHE. They believed that a moderate OHE reaction condition would be required to obtain high yields of alcohol and ester along with lower byproduct yields, and an accompanying optimum selectivity to desired products (alcohol and ester) of $66.4 \%$ was obtained. Therefore, esterification and hydrogenation are the feasible ways of efficiently upgrading bio-oil.

Most studies have used model compounds to conduct OHE reactions, such as acetic acid/formic acid, phenol, furfural and aldehyde, instead of crude bio-oil, as substrates to identify the products and the reaction network due to the complicated structure of raw bio-oil. OHE is identified as an improved and effective process to achieve a higher conversion of model compounds to stable alcohol/ester components. However, undesired results were obtained when OHE was transferred from model compounds to actual bio-oil. As such, AcOH could not be converted sufficiently by OHE [7,20]. Acids can be effectively converted to esters via esterification, but esterification does not work for aldehyde, phenol and ketone upgrading, and their unsaturated properties remain unchanged [21-23]. These limitations are mainly ascribed to the extremely complex multifunctional groups of bio-oil substrates, which give rise to their interactions and competing reactions (changing the solution $\mathrm{pH}$ value and active components). Various complex fractions of bio-oil are hard to upgrade just by the coupling reactions realized under a given reaction condition. Therefore, for actual bio-oil upgrading, we divided OHE into two steps to decrease the unsaturation and corrosiveness of bio-oil fractions.

In our previous work, we used a mixed model composition of bio-oil (MCB) as the reactant to investigate the effect of upgrading and understand the catalytic mechanism [8]. Based on the catalytic mechanism of OHE of $\mathrm{MCB}$, we focused on upgrading factual bio-oil catalysts via esterification and hydrogenation reactions over Mo (or Sn)-RN (for enhancing the catalytic hydrogenation activity [24-27]), which have been investigated as effective catalysts for esterification and hydrogenation processes [6,28,29].

\section{Results}

2.1. Characterization of RNs

\subsubsection{Chemical Compositions}

Table 1 shows the chemical compositions of RNs. The Ni contents of the Raney Ni and Mo-modified Raney Ni catalysts were both above 93\%. In the Sn-RN catalyst, the content of Sn was $5.7 \%$.

Table 1. Composition of precursor alloy and modified Raney Ni catalysts.

\begin{tabular}{cccc}
\hline \multirow{2}{*}{ Catalyst } & \multicolumn{3}{c}{ Mass Ratio/\% } \\
\cline { 2 - 4 } & $\mathbf{N i}$ & $\mathbf{A l}$ & $\mathbf{M}(\mathbf{M}=\mathbf{M o} / \mathbf{S n})$ \\
\hline Ni-Al alloy & 48.7 & 51.3 & 0 \\
Raney Ni & 93.6 & 6.4 & 0 \\
Mo-RN & 93.3 & 6.0 & $0.7(\mathrm{Mo})$ \\
Sn-RN & 86.7 & 7.6 & $5.7(\mathrm{Sn})$ \\
\hline
\end{tabular}

\subsubsection{XRD Analysis of Catalyst}

The XRD patterns of the Raney Ni catalyst and the modified Raney Ni catalysts are shown in Figure 1. In Figure 1, the typical peaks indexed with $2 \theta$ at approximately $44.51^{\circ}$, $51.85^{\circ}$ and $76.37^{\circ}$ were attributed to $\mathrm{RN}$ configurations [8]. Although the contents of $\mathrm{Al}$ 
and Sn were above 5\%, there was no obvious typical peak in the XRD patterns. Herein, it is confirmed that the Sn species were highly dispersed in the surface of Raney Ni.

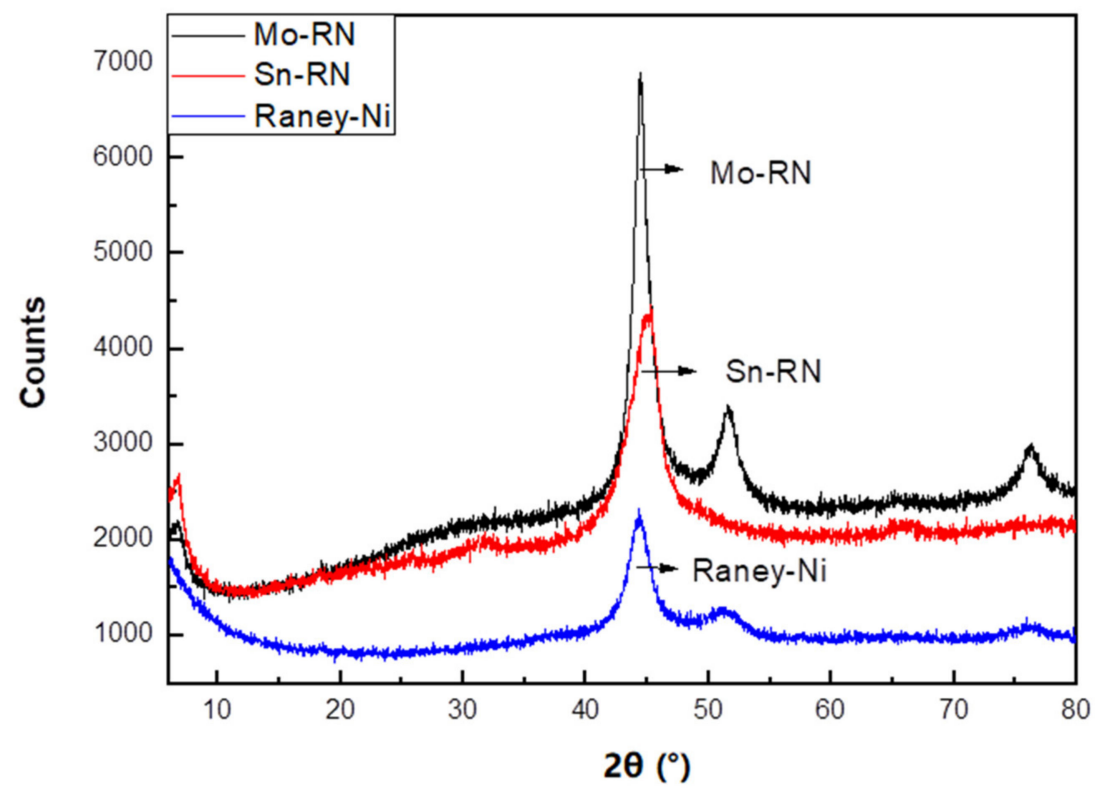

Figure 1. XRD patterns of Raney Ni catalyst and modified Raney Ni catalysts.

\subsection{Two Steps of Esterification and Hydrogenation over Raney Ni Catalyst}

In order to improve the stability of bio-oil and reduce the difficulty of hydrogenation of bio-oil, esterification was applied to pretreat the raw bio-oil within different amounts of methanol. The relative results are shown in Table 2, where, when the ratio of methanol and raw bio-oil increased, the yield of liquid products decreased slightly, which might be related to some low-molecular weight components of bio-oil being converted to gaseous products under $240{ }^{\circ} \mathrm{C}$. Although there is no obvious difference in the liquid product yield and char among different methanol/bio-oil weight ratios, the components were very different between raw bio-oil and the esterification products, especially the content change in alcohols, acids, esters and ketones and aldehydes; after esterification, the unstable components (acids, ketones and aldehydes) significantly decreased, while the alcohols and esters were remarkably increased (Table 3). These stable components are suitable for hydrogenation at mild conditions [30]. Meanwhile, the low char yields at different methanol/bio-oil mass ratios under $240{ }^{\circ} \mathrm{C}$ are mainly attributed to the esterification to reduce the unstable functional groups that led to polymerization and/or coking [30,31]. Of course, Table 2 also shows that the change in the methanol/bio-oil mass ratio was not the key factor for esterification's effectiveness.

Table 2. The liquid product yield after esterification pretreatment with different methanol/bio-oil mass ratios.

\begin{tabular}{cccc}
\hline & $\mathbf{1 : 1}^{\mathbf{a}}$ & $\mathbf{2 : 1}$ & $\mathbf{3 : 1}$ \\
\hline Liquid product yield $/ \% \mathrm{~b}$ & 91.13 & 90.52 & 85.66 \\
Char & 0.8 & 1.15 & 1.11 \\
\hline
\end{tabular}

a: the mass ratio of methanol and raw bio-oil in weight, free catalyst, $240{ }^{\circ} \mathrm{C}, 1 \mathrm{Mpa} \mathrm{H}_{2}, 3 \mathrm{~h} .{ }^{\mathrm{b}}$ : the liquid product components are classified and summarized in Table 3. 
Table 3. The distribution of the liquid products after esterification and catalytic hydrogenation with different alcohol oil ratios.

\begin{tabular}{cccccccc}
\hline & \multicolumn{7}{c}{ Yield of Different Compounds (\%) } \\
\cline { 2 - 8 } & Alcohols & Acids & Esters & $\begin{array}{c}\text { Ketones and } \\
\text { Aldehydes }\end{array}$ & Phenols & Ethers & Others \\
\hline $\begin{array}{c}\text { Raw } \\
\text { bio-oil }\end{array}$ & 5.79 & 49.04 & 4.74 & 28.87 & 7.35 & 2.79 & 1.42 \\
$1: 1^{\mathrm{a}} \mathrm{E}^{\mathrm{b}}$ & 18.58 & 14.09 & 38.97 & 16.95 & 6.97 & 2.97 & 1.47 \\
$1: 1^{\mathrm{a}} \mathrm{H}^{\mathrm{c}}$ & 56.32 & 7.34 & 30.10 & 0 & 4.59 & 0.83 & 0.82 \\
$2: 1^{\mathrm{a}} \mathrm{E}^{\mathrm{b}}$ & 20.43 & 9.99 & 40.74 & 16.86 & 6.51 & 3.52 & 0.95 \\
$2: 1^{\mathrm{a}} \mathrm{H}^{\mathrm{c}}$ & 60.35 & 6.00 & 29.13 & 0 & 3.48 & 1.04 & 0 \\
$3: 1^{\mathrm{a}} \mathrm{E}^{\mathrm{b}}$ & 21.34 & 6.62 & 46.16 & 16.19 & 6.14 & 3.27 & 1.28 \\
$3: 1^{\mathrm{a}} \mathrm{H}^{\mathrm{c}}$ & 61.23 & 4.32 & 31.28 & 0 & 2.39 & 0.78 & 0 \\
\hline
\end{tabular}

a: the weight ratio of methanol and raw bio-oil. " $\mathrm{E}$ " and " $\mathrm{H}$ " refer to esterification and hydrogenation, respectively.

b: esterification condition, $36.0 \mathrm{~g}$ feedstock (methanol/bio-oil, 3:1, 2:1, 1:1 in weight ratio), $240{ }^{\circ} \mathrm{C}, 1 \mathrm{Mpa}_{2}, 3 \mathrm{~h}$, free catalyst. ${ }^{c}$ : hydrogenation condition, $140{ }^{\circ} \mathrm{C}, 6 \mathrm{Mpa} \mathrm{H}_{2}, 4 \mathrm{~h}, 2 \mathrm{~g}$ Raney Ni, hydrogenation materials were the mixture following the esterification of methanol and raw bio-oil.

The distributions of the liquid products from the two steps of esterification and catalytic hydrogenation over the Raney Ni catalyst in different methanol/bio-oil mass ratios are shown in Table 3. Compared with the raw bio-oil, after esterification, the content of acids and ketones and aldehydes in the liquid products decreased significantly in each mass ratio (methanol/bio-oil) case, while the content of alcohols and esters increased obviously in each mass ratio case. These results indicate that the unstable fractions (acids, ketones and aldehydes) occurred due to effective esterification reactions under the solvothermal action of supercritical methanol. The conversion of the acids and the yield of esters increased obviously with the increase in the methanol/bio-oil mass ratio, which might be ascribed to the increase in alcohol that promotes the process of the esterification reaction. Meanwhile, when the methanol/bio-oil mass ratio increased, the content of alcohols and esters increased slightly (from 38.97 and $18.58 \%$ to 46.16 and $21.34 \%$, respectively), and the content of acids and ketones and aldehydes reduced slightly (from 14.09 and $16.95 \%$ to 6.62 and $16.19 \%$, respectively). It can be seen from Table 3 that the change in phenols and ethers contents in liquid products was not significant after esterification, which indicates that the esterification had little effect on these two fractions. Although there was no catalyst in the reactor, the ketones and aldehydes hydrogenated due to the presence of $\mathrm{H}_{2}$ and the solvothermal action, to some extent.

After the second step of hydrogenation, the composition distribution was quite different. Firstly, no ketones and aldehydes were detected in the reaction system after the hydrogenation process at $140{ }^{\circ} \mathrm{C}$ over the Raney $\mathrm{Ni}$ catalyst; they should be converted to alcohols [8]. For the phenols and acids, both of the contents decreased significantly. The phenols could be transferred to cyclohexanols over the Raney Ni catalyst [32-34]. The decreasing content of acids might be caused by the further esterification that happened between the remaining acids after esterification and methanol or other alcohols in the reaction system in the hydrogenation process. Moreover, it is worthy to note that the contents of esters and ethers were decreased, which might be due to some of the esters and ethers being hydrogenated to alcohols. Therefore, the hydrogenation of ketones and aldehydes, phenols, esters and ethers contributed to increasing the yield of alcohols. The above results imply that the unstable functional groups/components in bio-oil were effectively converted to stable components over the Raney Ni catalyst under a mild temperature $\left(140^{\circ} \mathrm{C}\right)$. However, with the increase in the methanol/bio-oil mass ratio from 1:1 to 1:3, the change in the content of alcohols, acids, esters, ketones and aldehydes, phenols and others was slight, demonstrating that increasing the amount of methanol did not effectively improve bio-oil upgrading. For example, the total content of stable compounds increased slightly from 87.25 (1:1) to $90.52 \%$ (1:2) and $93.24 \%$ (1:3). Hence, the methanol/bio-oil mass ratio of 1:1 was chosen for the following experiments. 


\subsection{Two Steps of Esterification and Hydrogenation of Bio-Oil over Modified Raney Ni Catalysts}

In this part, the mass ratio of methanol (or the mixture)/bio-oil was set to 1:1. The mixture derived from the first round of TEH was used instead of methanol, and a new bio-oil was used as the feedstock for the second round of TEH reactions.

As shown in Table 4, the quality of bio-oil improved after the hydrogenation of the first run of TEH over the Sn-RN or Mo-RN catalyst, with the content of acids and ketones and aldehydes significantly decreased; in particular, ketones and aldehydes were not detected, and the alcohols increased markedly. The performance of the Sn-RN catalyst for bio-oil upgrading may well be attributed to the $\mathrm{Sn}$ incorporation of Raney Ni that increases the total acidity, transforming oxygen-containing organics to hydrocarbons, and the low oxygenated selectivity in the bio-oil $[35,36]$. Compared to the result of the first run of TEH over the Raney Ni catalyst, the Mo-RN catalyst displayed a better bio-oil upgrading (hydrogenation) effect, while Sn-RN showed a relatively weaker upgrading effect than the Raney Ni catalyst. The Mo-modified Raney Ni catalyst showed the highest bio-oil upgrading performance among the three kinds of catalysts, and the role of Mo could be due to the Mo element enhancing the thermal stability of the Mo-RN catalyst and the $\mathrm{MoO}_{\mathrm{x}}$ species improving the hydrogenation activity of bio-oil [37,38]. It was proposed that the introduction of Mo could improve the thermal stability of Ni-based catalysts because of a strong interaction between Raney Ni and Mo species. The Mo element with a bigger atom radius inhibited the diffusion velocity of the nickel atom, reduced the accumulation of atoms and reduced the hydrogenation activity $[38,39]$.

Table 4. The product distribution after two steps of upgrading over modified Raney Ni catalysts.

\begin{tabular}{ccccccccc}
\hline & \multicolumn{7}{c}{ Contents of Different Compounds (\%) } \\
\cline { 2 - 9 } & & Alcohols & Acids & Esters & Ketones and Aldehydes & Phenols & Ethers & Others \\
\hline \multicolumn{2}{c}{ Raw bio-oil } & 5.79 & 49.04 & 4.74 & 28.87 & 7.35 & 2.79 & 1.42 \\
\hline \multirow{2}{*}{ Sn-RN } & $1: 1 \mathrm{E}$ & 18.58 & 14.09 & 38.97 & 16.95 & 6.97 & 2.97 & 1.47 \\
& $1: 1 \mathrm{H}$ & 54.62 & 7.53 & 30.40 & 0 & 5.48 & 1.04 & 0.93 \\
& $* 1: 1 \mathrm{E}^{\mathrm{a}}$ & 37.22 & 20.19 & 26.34 & 8.24 & 5.96 & 1.01 & 1.04 \\
& $1: 1 \mathrm{H}^{\mathrm{b}}$ & 63.27 & 5.32 & 25.28 & 0 & 4.79 & 0.98 & 0.36 \\
\hline \multirow{2}{*}{ Mo-RN } & $1: 1 \mathrm{E}$ & 18.58 & 14.09 & 38.97 & 16.95 & 6.97 & 2.97 & 1.47 \\
& $1: 1 \mathrm{H}$ & 61.06 & 5.44 & 29.10 & 0 & 2.89 & 0.75 & 0.76 \\
& $* 1: 1 \mathrm{E}^{\mathrm{a}}$ & 38.00 & 20.21 & 25.94 & 0.22 & 5.69 & 0.96 & 0.98 \\
& $1: 1 \mathrm{H}^{\mathrm{b}}$ & 66.89 & 3.21 & 26.71 & 0 & 2.01 & 0.32 & 0.86 \\
\hline
\end{tabular}

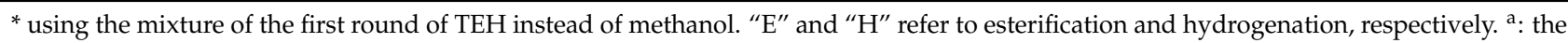
second-round esterification condition, $36.0 \mathrm{~g}$ feedstock (the mixture of the first round of TEH: raw bio-oil=1:1 in weight ratio), $240{ }^{\circ} \mathrm{C}$, $1 \mathrm{Mpa} \mathrm{H}_{2}, 3 \mathrm{~h}$, free catalyst. ${ }^{\mathrm{b}}$ : the second-round hydrogenation condition, $140{ }^{\circ} \mathrm{C}, 6 \mathrm{Mpa} \mathrm{H}_{2}, 4 \mathrm{~h}, 2.0 \mathrm{~g}$ Sn-RN or Mo-RN, the feedstock was the mixture derived from esterification of the second round of TEH.

After the mixture derived from the first round of TEH replaced methanol to carry out the second run of the esterification reaction, the alcohols and esters in the liquid products were changed to $37.22 \%(38.00 \%)$ and $26.34 \%(25.94 \%)$, respectively. The acids and ketones and aldehydes were about $20 \%$ and $8.0 \%$, respectively. This means that the mixture from the first round of TEH, instead of methanol, can also effectively allow esterification to take place and improve the stability of the bio-oil. When the second run of hydrogenation was conducted over the Sn-RN or Mo-RN catalyst, the distribution of liquid products changed obviously. For instance, the acids, phenols and ketones and aldehydes decreased significantly, and, in particular, no ketones and aldehydes were detected. The alcohols were increased markedly, and, in particular, the content of alcohols reached $66.89 \%$ in the Mo-RN case. This indicates that the mixture derived from the second run of esterification continued to take part in the hydrogenation reaction and exhibited an excellent effect for bio-oil upgrading. The contents of stable compounds were also enriched after the second round of TEH upgrading and increased from 13.32\% (raw bio-oil) to $87.25 \%$ (Raney $\mathrm{Ni}, \mathrm{TEH}$ ) and to $93.92 \%$ (Mo-Raney Ni, TEH). It can be seen that the modified Mo-RN 
catalyst has a higher ability of upgrading the bio-oil quality in the two rounds of the hydrogenation reaction.

2.4. Comparation between One Step Esterification-Hydrogenation and Two Steps of Esterification and Hydrogenation of Bio-Oil over Mo-Raney Ni Catalyst

As we know, the method of one-step esterification-hydrogenation for bio-oil upgrading was published in some research works [40,41]; for comparison, the Mo-RN catalyst with excellent performance in raw bio-oil improvement was chosen to investigate the hydrogenation performance in two methods (OHE and TEH). From Table 5, the variation trend of the product distributions using the two methods was quite similar, and no ketones and aldehydes were detected in the products. Additionally, the contents of acids, phenols and ethers all showed a downward trend. The alcohols and esters, as the target products (stable components), increased significantly after the esterification and hydrogenation reactions. However, the Mo-RN catalyst displayed a better upgrading performance in the TEH method, with higher alcohol and stable compound contents and lower acid contents. It can be inferred that the TEH method is more suitable for bio-oil upgrading because the TEH method of the esterification and hydrogenation reaction conditions is different, which is more favorable for bio-oil's complex components' saturation and stabilization step by step.

Table 5. The product distribution after two methods to upgrade bio-oil over Mo-Raney Ni catalyst.

\begin{tabular}{cccccccc}
\hline & \multicolumn{7}{c}{ Contents of Different Compounds (\%) } \\
\cline { 2 - 8 } & Alcohols & Acids & Esters & $\begin{array}{c}\text { Ketones and } \\
\text { Aldehydes }\end{array}$ & Phenols & Ethers & Others \\
\hline Raw & 5.79 & 49.04 & 4.74 & 28.87 & 7.35 & 2.79 & 1.42 \\
bio-oil & 53.61 & 6.77 & 33.66 & 0 & 3.84 & 0.68 & 0 \\
OHE & 61.06 & 5.44 & 29.10 & 0 & 2.89 & 0.75 & 0.76 \\
TEH &
\end{tabular}

OHE reaction condition: $36.0 \mathrm{~g}$ feedstock (methanol/ raw bio-oil $=1: 1 \mathrm{in}$ weight ratio), $240{ }^{\circ} \mathrm{C}, 6 \mathrm{Mpa} \mathrm{H}_{2}, 4 \mathrm{~h}, 0.5 \mathrm{~g}$ Mo-RN. TEH reaction condition: esterification reaction, $36.0 \mathrm{~g}$ feedstock (methanol/raw bio-oil = 1:1 in weight ratio), $240{ }^{\circ} \mathrm{C}, 1 \mathrm{Mpa} \mathrm{H}_{2}, 3 \mathrm{~h}$, free catalyst. Hydrogenation condition: $140{ }^{\circ} \mathrm{C}, 6 \mathrm{Mpa} \mathrm{H}_{2}, 4 \mathrm{~h}, 0.5 \mathrm{~g} \mathrm{Mo}-\mathrm{RN}$, the feedstock of hydrogenation was the mixture derived from the esterification of methanol and raw bio-oil.

\section{Materials and Methods}

\subsection{Materials}

Methanol ( $\geq 99.5 \%$, analytical reagent) and $\mathrm{SnCl}_{2} \cdot 2 \mathrm{H}_{2} \mathrm{O}$ were purchased from Beijing Hengzhang Chemical Co. Ltd. (Beijing, China). Ni-Al alloy powder and Mo-modified RN (Mo-RN) were purchased from Dalian Toyounger Chemical Co., Ltd. (Dalian, China).

\subsection{Preparation of Catalysts}

$\mathrm{Ni}-\mathrm{Al}$ alloy powder was slowly added to a $20 \mathrm{wt} \% \mathrm{NaOH}$ aqueous solution at $50{ }^{\circ} \mathrm{C}$. The solution was precipitated after $1.5 \mathrm{~h}$ of magnetic stirring at the temperature of $50{ }^{\circ} \mathrm{C}$. The solid phase was washed by distilled water until the $\mathrm{pH}$ reached $8-9$ and then by ethanol for 6 times. The prepared RN was stored in ethanol. Sn-modified RN (Sn-RN) was synthesized by dissolving $\mathrm{SnCl}_{2} \cdot 2 \mathrm{H}_{2} \mathrm{O}$ in $30 \mathrm{~mL}$ deionized water, adding this solution to reduced RN and heating the resulting mixture to $100{ }^{\circ} \mathrm{C}$ in a sealed vial for $1 \mathrm{~h}$. The required Sn-modified Raney $\mathrm{Ni}(\mathrm{Sn} \mathrm{RN})$ catalyst was formed.

\subsection{Catalyst Characterization}

The chemical compositions of RN were identified by inductively coupled plasmaatomic emission spectrometry (ICP-OES, OPTIMA 8000, PerkinElmer Instruments, Waltham, MA, USA). The catalyst was characterized by X-ray powder diffraction (XRD) which was performed on a Bruker Endeavor D4 (Bruker, Karlsruhe, Baden-Wurttemberg, Germany) with the settings of $40 \mathrm{kV}$ and $40 \mathrm{~mA}$ using $\mathrm{Cu}-\mathrm{K} \alpha$ radiation, and data were collected at steps of $0.02^{\circ}$ in the $2 \theta$ range of $5^{\circ}-80^{\circ}$; detailed information of catalysts was presented 
in our previous work. Scanning electron microscopy (SEM) images were recorded on a Hitachi S-4800 (Hitachi Limited, Tokyo, Japan) instrument operated at $20 \mathrm{kV}$.

\subsection{Esterification and Hydrogenation Processes}

Two steps of esterification and hydrogenation (TEH) of bio-oil were performed in a $100 \mathrm{~mL}$ stainless autoclave, as shown in Figure 2.

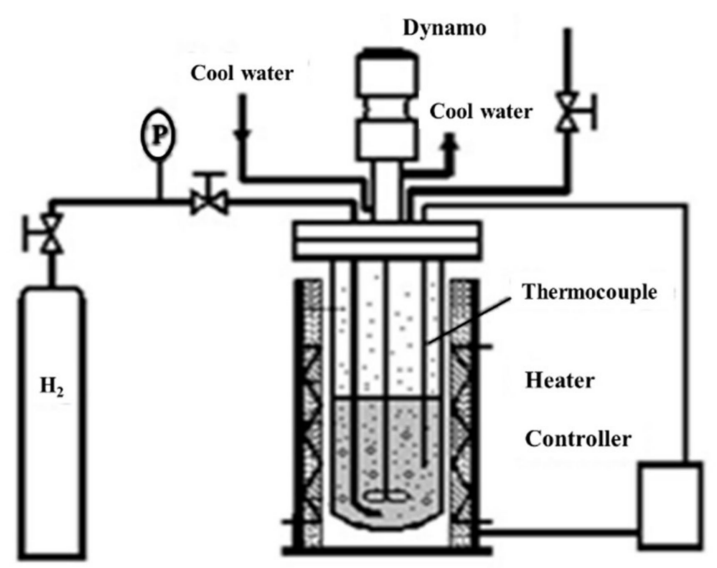

Figure 2. Schematic diagram of experimental apparatus.

In a typical esterification experiment, $36.0 \mathrm{~g}$ feedstock (methanol/bio-oil, 3:1, 2:1, 1:1 in weight ratio and the product of TEH/bio-oil, 1:1 in weight ratio) was loaded into a $100 \mathrm{~mL}$ reactor, which was sealed and purged with $\mathrm{H}_{2}$ for 3 times to exclude air without catalyst. The pressure was raised to $1.0 \mathrm{MPa}$, and the reaction temperature was set from $240{ }^{\circ} \mathrm{C}$ for $3 \mathrm{~h}$. After reaction, the autoclave was cooled down to room temperature, and then the liquid products were sampled by GC-MS analysis. The hydrogenation reaction was performed in the presence of $0.5 \mathrm{~g}$ Raney Ni catalysts. The feedstock of the hydrogenation reaction was the mixture following the esterification of methanol and raw bio-oil. Additionally, the pressure was set to $6 \mathrm{MPa}$, and the reaction temperature was set from $140{ }^{\circ} \mathrm{C}$ for $4 \mathrm{~h}$. The products were sampled by GC-MS analysis.

In the second run of TEH, we used the mixture derived from the first run of TEH, instead of methanol, to investigate raw bio-oil upgrading. In a typical experiment, the feedstock was the mixture of the product from the first run of TEH and raw bio-oil (the mixture derived from the first run of TEH/raw bio-oil was 1:1 in mass ratio). The following step was the same as that for TEH.

\subsection{Product Analysis}

Gas chromatography/mass spectrometry (GC-MS, Trace 2000, Thermo-Finnigan Inc., San Francisco, CA, USA) was used to determine the types and content of compounds in the raw bio-oil and the upgrading product. The separation was realized on a column of HPINNOWAX (Agilent Technologies, Palo Alto, CA, USA), $30 \mathrm{~m} \times 0.25 \mathrm{~mm} \times 0.25 \mathrm{~lm}$, and the oven temperature program was $40^{\circ} \mathrm{C}$ (holding for $8 \mathrm{~min}$ ) at $6 / \mathrm{min}$ to $240{ }^{\circ} \mathrm{C}$ (holding for $30 \mathrm{~min})$. The quantitative analysis of the compounds was carried out on an Agilent 7890 GC (Agilent Technologies, Palo Alto, CA, USA) with a flame ionization detector (FID), using acetophenone as the internal standard at the same capillary column and temperature program as the GC-MS analysis. 


\subsection{Feedstock Conversion, Product Quantification and Yield Calculations}

The yield of alcohols, acids, esters, ketones and aldehydes, phenols, ethers and others in the feedstock (bio-oil) and resultant products were calculated by the weight comparison between the recovered compounds and the feedstock, as shown in Equations (1) (7), respectively.

$$
\begin{aligned}
& \text { Yield }_{\text {alcohols }}(\%)=\frac{\frac{A_{a} M_{I S}}{A_{I S}}}{M_{0}} \times 100 \% \\
& \text { Yield }_{\text {acids }}(\%)=\frac{\frac{A_{a s} M_{I S}}{A_{I S}}}{M_{0}} \times 100 \% \\
& \text { Yield }_{\text {esters }}(\%)=\frac{\frac{A_{e} M_{I S}}{A_{I S}}}{M_{0}} \times 100 \% \\
& \text { Yield ketones \& aldehydes }(\%)=\frac{\frac{A_{K A} M_{I S}}{A_{I S}}}{M_{0}} \times 100 \% \\
& \text { Yield }_{\text {phenols }}(\%)=\frac{\frac{A_{p} M_{I S}}{A_{I S}}}{M_{0}} \times 100 \% \\
& \text { Yield }_{\text {ethers }}(\%)=\frac{\frac{A_{e s} M_{I S}}{A_{I S}}}{M_{0}} \times 100 \% \\
& \text { Yield }_{\text {others }}(\%)=\frac{\frac{A_{0} M_{I S}}{A_{I S}}}{M_{0}} \times 100 \%
\end{aligned}
$$

In the equations, $M_{0}$ : the weight of the feedstock; $M_{I S}$ : the weight of the internal standard; $A_{I S}$ : the peak area of the internal standard; $A_{a}$ : the peak area of alcohols; $A_{a s}$ : the peak area of acids; $A_{e}$ : the peak area of esters; $A_{K A}$ : the peak area of ketones and aldehydes; $A_{p}$ : the peak area of phenols; $A_{e s}$ : the peak area of ethers; $A_{o}$ : the peak area of others.

\section{Conclusions}

In this paper, we applied the TEH method to upgrade the light fraction of raw bio-oil over Raney Ni and modified Raney Ni (Sn-RN and Mo-RN) catalysts. After the esterification (the first step of TEH) without a catalyst, the content of alcohols and esters markedly increased from $5.79 \%$ and $4.74 \%$ to 18.58 and $38.97 \%$, respectively, while the content of acids and ketones and aldehydes obviously decreased from $49.04 \%$ and $28.87 \%$ to $14.09 \%$ and $16.95 \%$, showing an improvement in the component stability of the bio-oil that helped to promote the hydrogenation reaction. The hydrogenation (the second step of TEH) was conducted over Raney Ni, Sn-RN and Mo-RN catalysts, and the results show that no ketone and aldehyde compounds were detected in the liquid products in all catalyst cases, and the acid content further decreased to $7.34 \%, 7.53 \%$ and $5.44 \%$, respectively. The stable components (the alcohols and esters) increased significantly from $57.55 \%$ to $86.42 \%, 85.02 \%$ and $90.61 \%$, respectively. The results of the TEH method exhibit excellent bio-oil upgrading performance. The second run of TEH also displayed a charming bio-oil upgrading effect over the Mo-RN catalyst due to the higher hydrogenation activity from Raney Ni combined with acid $\mathrm{MoO}_{x}$ species. Moreover, the mixture derived from the first run of TEH can be used, instead of methanol, as a solvent to upgrade bio-oil, which is very conducive to reducing the process of the product and solvent separation, improving the utilization of methanol and reducing energy consumption. Finally, the bio-oil upgrading performance was investigated in two methods (OHE and TEH) over the Mo-RN catalyst, and the variation trend of the product distributions using the two methods was quite similar, but a better upgrading performance in the TEH method was obtained with higher alcohol and stable compound contents and lower acid contents. The TEH method is more suitable for bio-oil 
upgrading because the TEH method is more favorable to bio-oil's complex components' saturation and stabilization step by step.

Author Contributions: Conceptualization, L.M. and C.W. (Chenguagn Wang); methodology, X.Z.; software, Y.X.; validation, Y.X., W.L. and L.M.; formal analysis, C.W. (Congwei Wang); investigation, L.Z.; resources, X.Z.; data curation, Y.X. and L.Z.; writing—original draft preparation, Y.X. and W.L.; writing—review and editing, W.L.; visualization, L.Z.; supervision, Q.Z.; project administration, Y.X., X.Z. and L.M. All authors have read and agreed to the published version of the manuscript.

Funding: This research was funded by the Natural Science Foundation of China (No. 51676191), Strategic Priority Research Program of the Chinese Academy of Sciences (XDA 21060102), Local Innovative and Research Teams Project of Guangdong Pearl River Talents Program (No. 2017BT01N092), the Youth Science and Technology Innovation Talents of Guangdong Province (No. 2015TQ01N652) and the Youth Innovation Promotion Association of Chinese Academy of Sciences (2016313).

Data Availability Statement: All data included in this study are available upon request by contact with the first author or corresponding author.

Conflicts of Interest: The authors declare no conflict of interest.

\section{References}

1. Xu, X.; Yang, Y.; Xiao, C.; Zhang, X. Energy balance and global warming potential of corn straw-based bioethanol in China from a life cycle perspective. Int. J. Green Energy 2018, 15, 296-304. [CrossRef]

2. Zhu, L.; Li, K.; Ding, H.; Zhu, X. Studying on properties of bio-oil by adding blended additive during aging. Fuel 2018, 211, 704-711. [CrossRef]

3. Zhang, S.; Yan, Y.; Li, T.; Ren, Z. Upgrading of liquid fuel from the pyrolysis of biomass. Bioresour. Technol. 2005, 96, 545-550. [CrossRef]

4. Bu, Q.; Lei, H.; Zacher, A.H.; Wang, L.; Ren, S.; Liang, J.; Wei, Y.; Liu, Y.; Tang, J.; Zhang, Q.; et al. A review of catalytic hydrodeoxygenation of lignin-derived phenols from biomass pyrolysis. Bioresour. Technol. 2012, 124, 470-477. [CrossRef]

5. Yang, Z.; Kumar, A.; Huhnke, R.L. Review of recent developments to improve storage and transportation stability of bio-oil. Renew. Sustain. Energy Rev. 2015, 50, 859-870. [CrossRef]

6. Horáček, J.; Kubička, D. Bio-oil hydrotreating over conventional CoMo \& NiMo catalysts: The role of reaction conditions and additives. Fuel 2017, 198, 49-57. [CrossRef]

7. Chen, J.; Cai, Q.; Lu, L.; Leng, F.; Wang, S. Upgrading of the Acid-Rich Fraction of Bio-oil by Catalytic Hydrogenation-Esterification. ACS Sustain. Chem. Eng. 2016, 5, 1073-1081. [CrossRef]

8. Xu, Y.; Zhang, L.; Chang, J.; Zhang, X.; Ma, L.; Wang, T.; Zhang, Q. One step hydrogenation-esterification of model compounds and bio-oil to alcohols and esters over Raney Ni catalysts. Energy Convers. Manag. 2016, 108, 78-84. [CrossRef]

9. Xu, Y.; Li, Y.; Wang, C.; Wang, C.; Ma, L.; Wang, T.; Zhang, X.; Zhang, Q. In-situ hydrogenation of model compounds and raw bio-oil over Ni/CMK-3 catalyst. Fuel Process. Technol. 2017, 161, 226-231. [CrossRef]

10. Li, F.; Yuan, Y.; Huang, Z.; Chen, B.; Wang, F. Sustainable production of aromatics from bio-oils through combined catalytic upgrading with in situ generated hydrogen. Appl. Catal. B Environ. 2015, 165, 547-554. [CrossRef]

11. Shen, P.; Wei, R.; Zhu, M.Y.; Pan, D.; Xu, S.; Gao, L.; Xiao, G. Hydrodeoxygenation of Octanoic Acid over the Mo-Doped CeO2 -Supported Bimetal Catalysts: The Role of Mo. Chemistryselect 2018, 3, 4786-4796. [CrossRef]

12. Balat, M.; Balat, M.; Kirtay, E.; Balat, H. Main routes for the thermo-conversion of biomass into fuels and chemicals. Part 1: Pyrolysis systems. Energy Convers. Manag. 2009, 50, 3147-3157. [CrossRef]

13. Wang, S.; Cai, Q.; Chen, J.; Zhang, L.; Zhu, L.; Luo, Z. Co-cracking of bio-oil model compound mixtures and ethanol over different metal oxide-modified HZSM-5 catalysts. Fuel 2015, 160, 534-543. [CrossRef]

14. Remón, J.; Broust, F.; Valette, J.; Chhiti, Y.; Alava, I.; Fernández-Akarregi, A.R.; Arauzo, J.; Garcia, L. Production of a hydrogen-rich gas from fast pyrolysis bio-oils: Comparison between homogeneous and catalytic steam reforming routes. Int. J. Hydrogen Energy 2014, 39, 171-182. [CrossRef]

15. Tang, Y.; Miao, S.; Shanks, B.H.; Zheng, X. Bifunctional mesoporous organic-inorganic hybrid silica for combined one-step hydrogenation/esterification. Appl. Catal. A Gen. 2010, 375, 310-317. [CrossRef]

16. Tang, Y.; Miao, S.; Mo, L.; Zheng, X.; Shanks, B.H. One-Step Hydrogenation/Esterification Activity Enhancement over Bifunctional Mesoporous Organic-Inorganic Hybrid Silicas. Top. Catal. 2013, 56, 1804-1813. [CrossRef]

17. Tang, Y.; Miao, S.; Pham, H.N.; Datye, A.; Zheng, X.; Shanks, B.H. Enhancement of Pt catalytic activity in the hydrogenation of aldehydes. Appl. Catal. A Gen. 2011, 406, 81-88. [CrossRef]

18. Tang, Y.; Yu, W.J.; Mo, L.Y.; Lou, H.; Zheng, X.M. One-step hydrogenation-esterification of aldehyde and acid to ester Over Bifunctional Pt catlysts: A model reaction as novel route for catalytic upgrading of fast pyrolysis bio-oil. Energy Fuel 2008, 22, 3484-3488. [CrossRef] 
19. Yu, W.; Tang, Y.; Mo, L.; Chen, P.; Lou, H.; Zheng, X. One-step hydrogenation-esterification of furfural and acetic acid over bifunctional Pd catalysts for bio-oil upgrading. Bioresour. Technol. 2011, 102, 8241-8246. [CrossRef]

20. Yu, W.; Tang, Y.; Mo, L.; Chen, P.; Lou, H.; Zheng, X. Bifunctional Pd/Al-SBA-15 catalyzed one-step hydrogenation-esterification of furfural and acetic acid: A model reaction for catalytic upgrading of bio-oil. Catal. Commun. 2011, 13, 35-39. [CrossRef]

21. Wang, J.-J.; Chang, J.; Fan, J. Upgrading of Bio-oil by Catalytic Esterification and Determination of Acid Number for Evaluating Esterification Degree. Energy Fuels 2010, 24, 3251-3255. [CrossRef]

22. Zhang, X.; Chen, L.; Kong, W.; Wang, T.; Zhang, Q.; Long, J.; Xu, Y.; Ma, L. Upgrading of bio-oil to boiler fuel by catalytic hydrotreatment and esterification in an efficient process. Energy 2015, 84, 83-90. [CrossRef]

23. Xiu, S.; Shahbazi, A. Bio-oil production and upgrading research: A review. Renew. Sustain. Energy Rev. 2012, 16, 4406-4414. [CrossRef]

24. Wan, H.; Chaudhari, R.V.; Subramaniam, B. Catalytic Hydroprocessing of p-Cresol: Metal, Solvent and Mass-Transfer Effects. Top. Catal. 2012, 55, 129-139. [CrossRef]

25. Bykova, M.V.A.; Rekhtina, M.A.; Lebedev, M.; Zavarukhin, S.G.; Kaichev, V.V.; Venderbosch, R.H.; Yakovlev, V.A. Hydrotreatment of 2-Methoxyphenol over High Ni-Loaded Sol-Gel Catalysts: The Influence of Mo on Catalyst Activity and Reaction Pathways. Chemistryselect 2018, 3, 5153-5164. [CrossRef]

26. Şenol, O.; Ryymin, E.-M.; Viljava, T.-R.; Krause, A. Effect of hydrogen sulphide on the hydrodeoxygenation of aromatic and aliphatic oxygenates on sulphided catalysts. J. Mol. Catal. A Chem. 2007, 277, 107-112. [CrossRef]

27. Patel, B.; Arcelus-Arrillaga, P.; Izadpanah, A.; Hellgardt, K. Catalytic Hydrotreatment of algal biocrude from fast Hydrothermal Liquefaction. Renew. Energy 2017, 101, 1094-1101. [CrossRef]

28. Oregui-Bengoechea, M.; Gandarias, I.; Arias, P.L.; Barth, T. Unraveling the Role of Formic Acid and the Type of Solvent in the Catalytic Conversion of Lignin: A Holistic Approach. ChemSusChem 2017, 10, 754-766. [CrossRef] [PubMed]

29. Furimsky, E. Catalytic hydrodeoxygenation. Appl. Catal. A Gen. 2000, 199, 147-190. [CrossRef]

30. Bouxin, F.P.; Strub, H.; Dutta, T.; Aguilhon, J.; Morgan, T.J.; Mingardon, F.; Konda, M.; Singh, S.; Simmons, B.; George, A. Elucidating transfer hydrogenation mechanisms in non-catalytic lignin depolymerization. Green Chem. 2018, 20, 3566-3580. [CrossRef]

31. Sordakis, K.; Tang, C.H.; Vogt, L.K.; Junge, H.; Dyson, P.J.; Beller, M.; Laurenczy, G. Homogeneous Catalysis for Sustainable Hydrogen Storage in Formic Acid and Alcohols. Chem. Rev. 2018, 118, 372-433. [CrossRef] [PubMed]

32. Putra RD, D.; Trajano, H.L.; Liu, S.D.; Lee, H.; Smith, K.; Kim, C.S. In-situ glycerol aqueous phase reforming and phenol hydrogenation over Raney Ni (R). Chem. Eng. J. 2018, 350, 181-191. [CrossRef]

33. Xu, Y.; Long, J.; Liu, Q.; Li, Y.; Wang, C.; Zhang, Q.; Lv, W.; Zhang, X.; Qiu, S.; Wang, T.; et al. In situ Hydrogenation of Model Compounds and Raw Bio-Oil over Raney Ni Catalyst. Energy Convers. Manag. 2015, 89, 188-196. [CrossRef]

34. Xiang, Y.Z.; Ma, L.; Lu, C.S.; Zhang, Q.F.; Li, X.N. Aqueous system for the improved hydrogenation of phenol and its derivatives. Green Chem. 2008, 10, 939-943. [CrossRef]

35. Galarza, E.D.; Fermanelli, C.S.; Pierella, L.B.; Saux, C.; Renzini, M.S. Influence of the Sn incorporation method in ZSM-11 zeolites in the distribution of bio-oil products obtained from biomass pyrolysis. J. Anal. Appl. Pyrolysis 2021, 156, 105116. [CrossRef]

36. Xiong, Y.; Hou, G.; Fan, Y.; Li, X.; Yin, H. The deterioration of bio-oil and catalyst during the catalytic upgrading of biomass pyrolysis volatiles. Energy Sources Part A Recover. Util. Environ. Eff. 2020, 1-15. [CrossRef]

37. Lei, J.X.; Shi, Q.J. Effect of Mo on properties of Ni-B $/ \gamma-\mathrm{Al}_{2} \mathrm{O}_{3}$ amorphous alloy catalyst for liquid-phase furfural hydrogenation to furfural alcohol. Nonferr. Metal. 2007, 59, 58-61.

38. Zhang, Y.F.; Xie, Y.C.; Xiao, N.H.; Han, W.; Tang, Y.Q. Effect of MgO and La2O3 additives Ni methanation catalyst. Petrochem. Technol. 1985, 14, 141-148.

39. Shi, Q.J.; Li, F.Y.; Luo, L.T.; Zhang, X.H. Effects of heavy rare earth elements on properties of amorphous NiB alloy. J. Chin. Rare Earth Soc. 2003, 21, 449.

40. Zhang, M.J.; Li, W.Z.; Zu, S.; Huo, W.; Zhu, X.F.; Wang, Z.Y. Catalytic Hydrogenation for Bio-Oil Upgrading by a Supported NiMoB Amorphous Alloy. Chem. Eng. Technol. 2013, 36, 2108-2116. [CrossRef]

41. Lian, X.; Xue, Y.; Zhao, Z.; Xu, G.; Han, S.; Yu, H. Progress on upgrading methods of bio-oil: A review. Int. J. Energy Res. 2017, 41, 1798-1816. [CrossRef] 